\title{
UV-Triggered Polymerization, Deposition, and Patterning of Plant Phenolic Compounds
}

\author{
Farid Behboodi-Sadabad, Huijie Zhang, Vanessa Trouillet, Alexander Welle, \\ Nicolas Plumeré, and Pavel A. Levkin**
}

Plant-derived phenolic compounds, rich in catechol and pyrogallol moieties, can form multifunctional coatings on various substrates following polymerization under mildly alkaline conditions. Despite many appealing features of such coatings, the difficulty to control polymerization of phenolic compounds spatially and temporally limits their number of potential applications. In this study, it is demonstrated that UV irradiation can trigger oxidative polymerization and deposition of plant-derived phenolic compounds, which opens the possibility to create 2D gradients and patterns of polyphenol coatings and control this polymerization temporally. UV-vis spectroscopy, electrospray ionization mass spectrometry, and cyclic voltammetry analyses are used to investigate the UV-induced polymerization of several plant-derived phenolic compounds including pyrogallol, tannic acid, caffeic acid, and gallic acid. Formation of polyphenol coatings on polar and nonpolar substrates after UV irradiation has been studied using water contact angle measurements, atomic force microscopy, time of flight secondary ion mass spectrometry, and X-ray photoelectron spectroscopy (XPS). The possibility to use UV-light to accelerate polymerization of phenolic compounds and perform micropatterning can extend the scope of potential applications of the large class of structurally diverse plant-derived phenolic compounds.

materials by simple immersion of objects into a dopamine solution under basic conditions, ${ }^{[7]}$ in the presence of oxidants, ${ }^{[4 a, 8]}$ and under UV irradiation. ${ }^{[9]}$

Recently it was shown that different plant-derived phenolic compounds isolated from various plants, and rich in 1,2-dihydroxybenzene (catechol) and 1,2,3-trihydroxybenzene (pyrogallol, PG) moieties, could also form nanocoatings following polymerization using enzymes, ${ }^{[10]}$ coordination complexes, ${ }^{[11]}$ or using mildly alkaline solutions in the presence of dissolved oxygen. ${ }^{[7 b, 12]}$ In comparison to polydopamine, coatings based on plant phenolic compounds were found to possess more rapid adhesion rate, lower cost, excellent availability, and good structural diversity. ${ }^{[11 a, 13]}$ Phenolic compounds, found in various plant-derived foods (for example, fruits, vegetables, cereals, chocolate) and beverages (for example, tea, coffee, beer, wine) are known to be an important part of the defense system of plants. ${ }^{[14]}$ Plant phenolics show antioxi-

\section{Introduction}

The ability to control surface properties via functional coatings is fundamentally important in various applications. ${ }^{[1]}$ Recently, mussel adhesive proteins and their analogs containing multiple 3,4-dihydroxyphenylalanine (DOPA) moieties inspired many groups to use catechol (1,2-dihydroxyphenyl)-containing molecules for surface coating and functionalization, ${ }^{[2]}$ nanoparticles fabrication and modification, ${ }^{[3]}$ surfaces with special wettability, ${ }^{[4]}$ and development of new hydrogels ${ }^{[5]}$ and membrane. ${ }^{[6]}$ Dopamine, which is structurally similar to DOPA, has been found to form versatile polydopamine coatings on different

\footnotetext{
F. Behboodi-Sadabad, Dr. P. A. Levkin Institute of Toxicology and Genetics Institute of Organic Chemistry Karlsruhe Institute of Technology 76021 Karlsruhe, Germany E-mail: levkin@kit.edu H. Zhang, Dr. N. Plumeré Center for Electrochemical Sciences Ruhr-Universität Bochum D-44780 Bochum, Germany
} dant and anticancer effect. ${ }^{[14,15]}$ Long-term use of plant phenolics can eliminate the destructive effect of undesired reactive oxygen or nitrogen species in the body. ${ }^{[15]}$ Furthermore, plant phenolics are able to chelate metal ions, ${ }^{[16]}$ interact with surfaces and materials via charge-charge, charge-dipole, and covalent bonds, ${ }^{[16]}$ quench reactive radical species, and interact with oxidizing agents. ${ }^{[17]}$ Oxidized catechol and pyrogallol moieties enable antimicrobial activity of plant phenolics. ${ }^{[18]}$

Various lithographic techniques such as soft lithography and dip-pen lithography have been developed for surface patterning, ${ }^{[19]}$ yet most of the patterning methods are not applicable for the formation of gradients or for the fabrication

\author{
V. Trouillet \\ Institute for Applied Materials \\ and Karlsruhe Nano Micro Facility \\ Karlsruhe Institute of Technology \\ 76021 Karlsruhe, Germany \\ Dr. A. Welle \\ Institute of Functional Interfaces \\ and Karlsruhe Nano Micro Facility \\ Karlsruhe Institute of Technology \\ 76021 Karlsruhe, Germany
}


of patterns inside closed microfluidic channels or on curved surfaces. Creating patterns of functional structures within microfluidic channels or capillaries is crucial in research areas ranging from micro- and nanofluidics, ${ }^{[20]}$ analytical chemistry, ${ }^{[21]}$ drug delivery, ${ }^{[22]}$ clinical and diagnostics devices, ${ }^{[23]}$ to separation science. ${ }^{[24]}$

Coatings based on polyphenols can potentially lead to a lot of useful applications. However, the ability to control polyphenol nanocoatings spatially and temporally would significantly extend the number of potential applications. Until now, to the best of our knowledge, no methods for patterning plantderived phenolic compounds have been reported. Recently, we showed that dopamine polymerization and deposition could be accelerated by UV irradiation. ${ }^{[9,25]}$ In this paper, we demonstrate for the first time that the UV irradiation could induce oxidation and polymerization of various plant-derived phenolic compounds. The effect of UV on plant phenolic compounds was investigated using UV-vis spectroscopy, electrospray ionization mass spectrometry (ESI-MS), and cyclic voltammetry (CV). Various plant-derived phenolic compounds including PG, tannic acid (TA), caffeic acid (CA), and gallic acid (GA) could be polymerized under UV irradiation. We used UV-assisted polymerization and deposition of plant phenolic compounds to make polyphenol nanocoatings on polar and nonpolar substrates as well as to create gradients of polyphenol coatings. The ability to use UV-l ght to trigger polymerization and deposition of phenolic compounds opens the possibility to create polyphenol patterns and gradients within microfluidic channels, which was demonstrated by creating a pattern of PG inside a fused silica capillary. The use of UV-1 ght to accelerate formation of polyphenol nanocoatings opens the possibility for the photolithographic patterning of functional polyphenolic nanocoatings on various substrates, extending the scope of potential applications of plant polyphenols.

\section{Results and Discussion}

In order to realize the oxidative effect of UV irradiation, UV-vis spectra of 1,2,3-trihydroxybenzene (PG), TA, 3,4,5-trihydroxybenzoic acid (GA), and 3-(3,4-dihydroxyphenyl)-2-propenoic acid (CA) (Figure 1), representing some of the most common phenolic compounds derived from plants, ${ }^{[26]}$ in variety of acidic and basic solutions were measured. Kinetics and $\mathrm{pH}$ dependence of oxidation both in the dark and under UV irradiation (260 nm, $10 \mathrm{~mW} \mathrm{~cm}{ }^{-2}$ ) were investigated for each compound at $30 \mathrm{~min}$ time intervals for $2 \mathrm{~h}$ (Figure 2). Our results show that UV irradiation of PG, TA, GA, and CA even under acidic $\mathrm{pH}$ leads to a change of color of solutions and increase of UV absorbance. Figure 2A demonstrates the corresponding color change of the PG and TA solutions irradiated with UV light in comparison with those stored in the dark. UV-vis spectra of irradiated PG $\left(0.2 \mathrm{mg} \mathrm{mL}^{-1}\right.$, acetate buffer at $\left.\mathrm{pH} 5.0\right)$ and TA (0.2 $\mathrm{mg} \mathrm{mL}^{-1}$, phosphate buffer at $\left.\mathrm{pH} 7.0\right)$ solutions shifted to higher absorbance at $350 \mathrm{~nm}$ along with increasing UV irradiation time, while absorbance of non-irradiated samples remained unchanged (Figure 2B,C). Increased absorbance of solutions after UV irradiation was also observed for PG, TA, $\mathrm{GA}$, and CA at different $\mathrm{pH}$ conditions (both acidic and basic) (Figures S1-S9, Supporting Information). The increase of absorbance at $350 \mathrm{~nm}$ as a function of time for each sample is plotted in Figure 2D. For example, normalized UV absorbance at $350 \mathrm{~nm}$ of PG (pH 5.0), TA (pH 7.0), GA (pH 6.0), and $\mathrm{CA}(\mathrm{pH}$ 6.0) solutions after $2 \mathrm{~h}$ of UV irradiation increased to

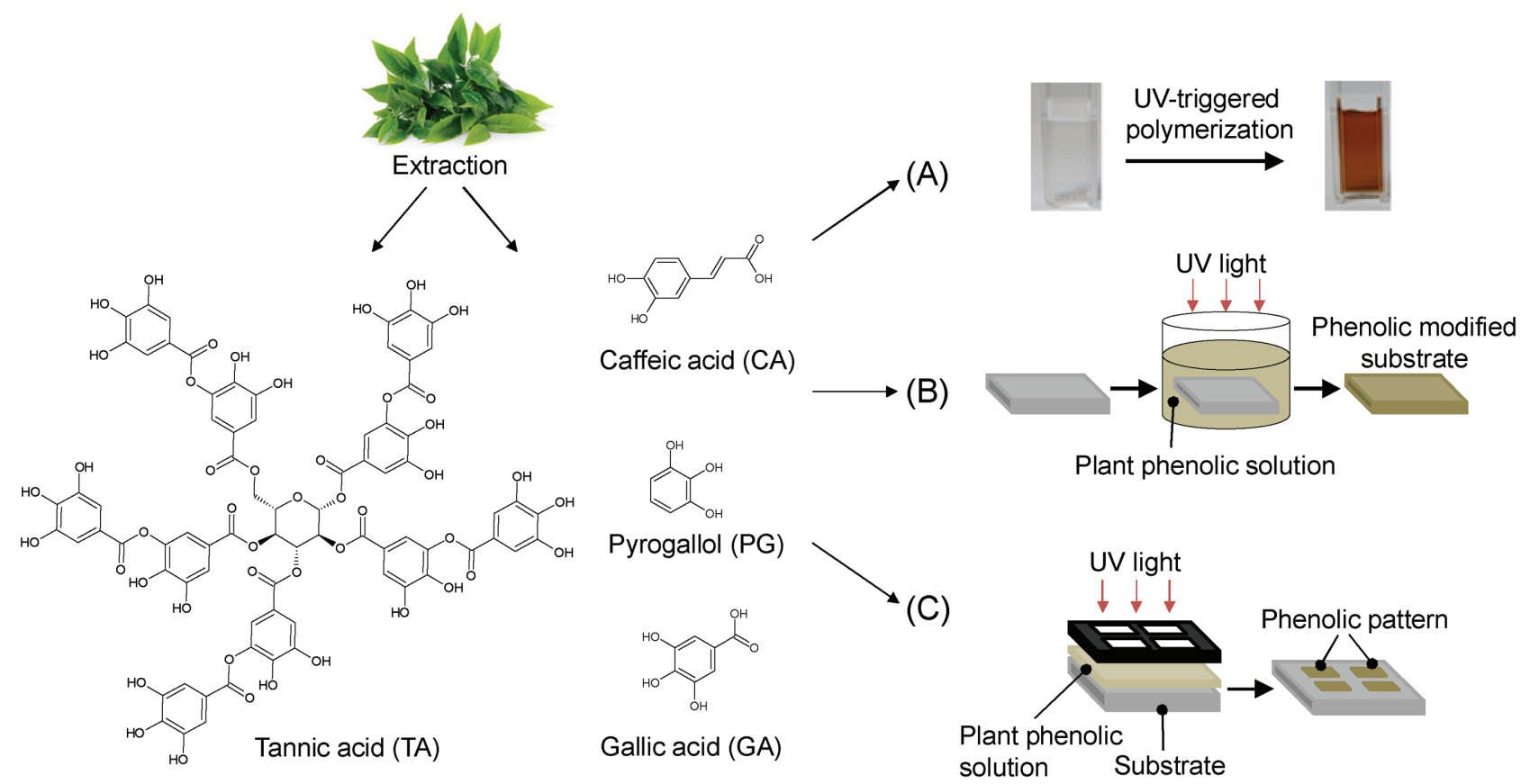

Figure 1. Schematic representation of the UV-induced A) polymerization, B) deposition, and C) patterning of plant-derived phenolics: tannic acid (TA), pyrogallol (PG), gallic acid (CA), and caffeic acid (CA). 
(A)

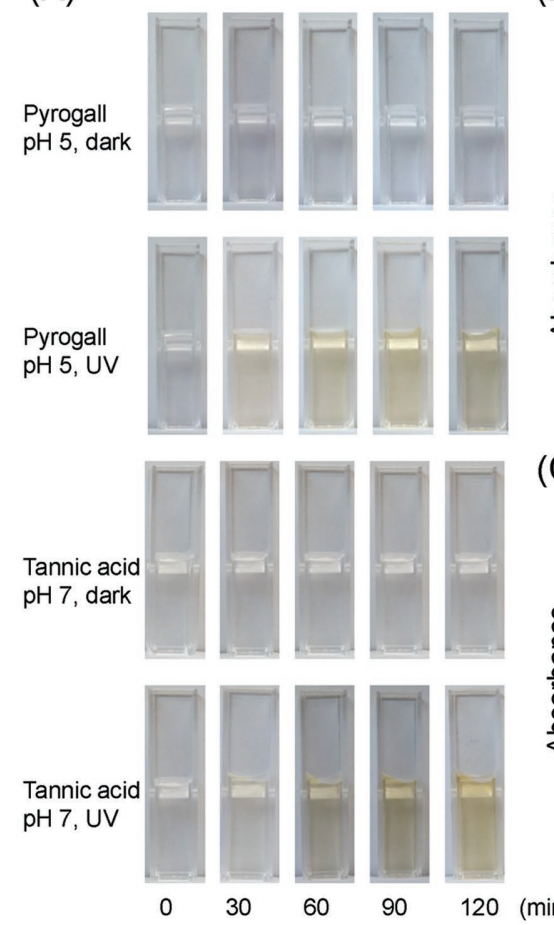

(D)

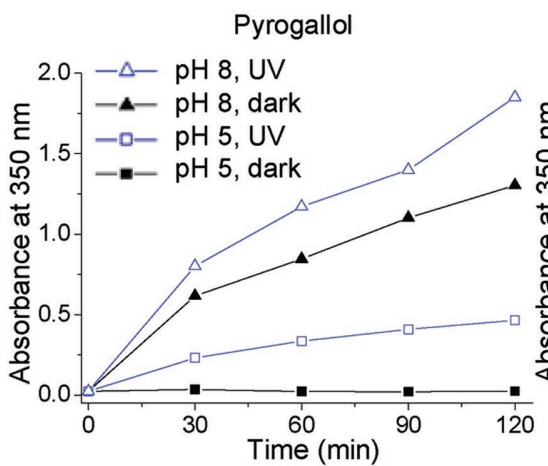

(B)
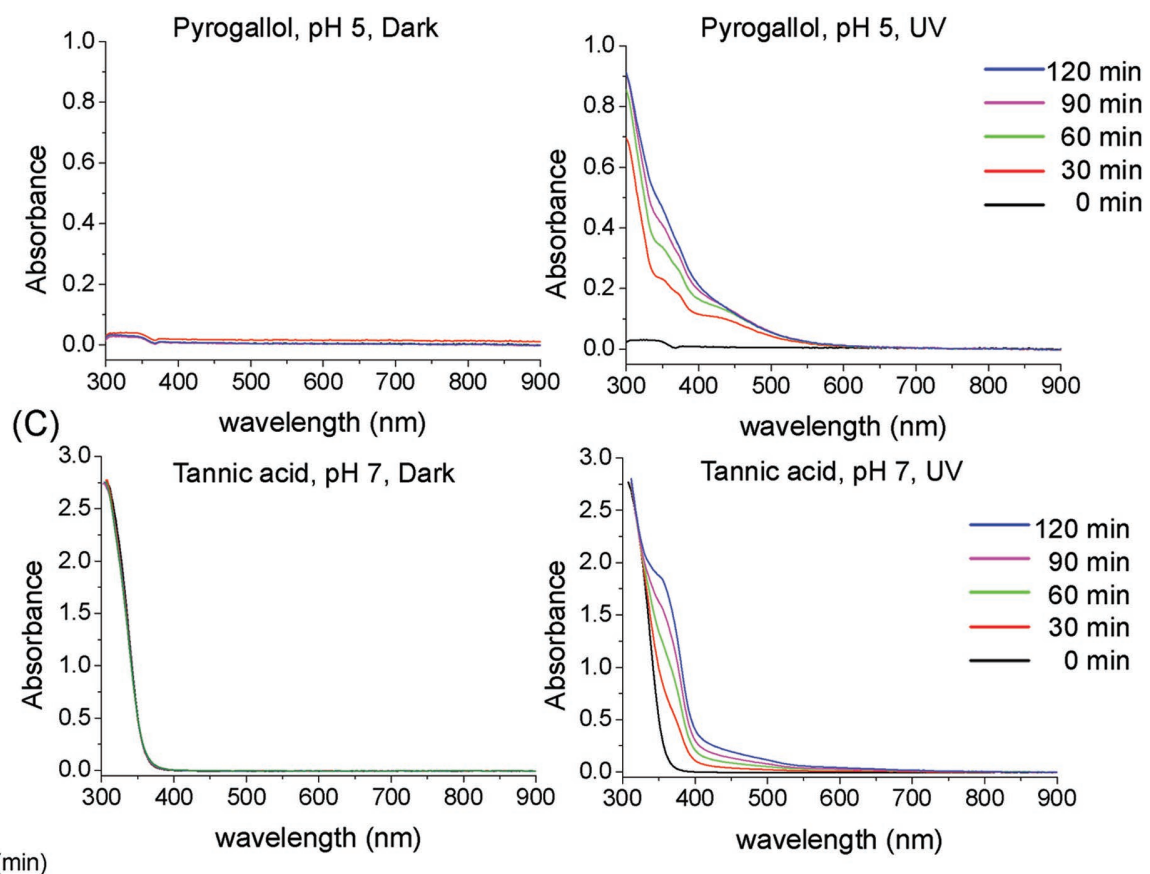

(E)
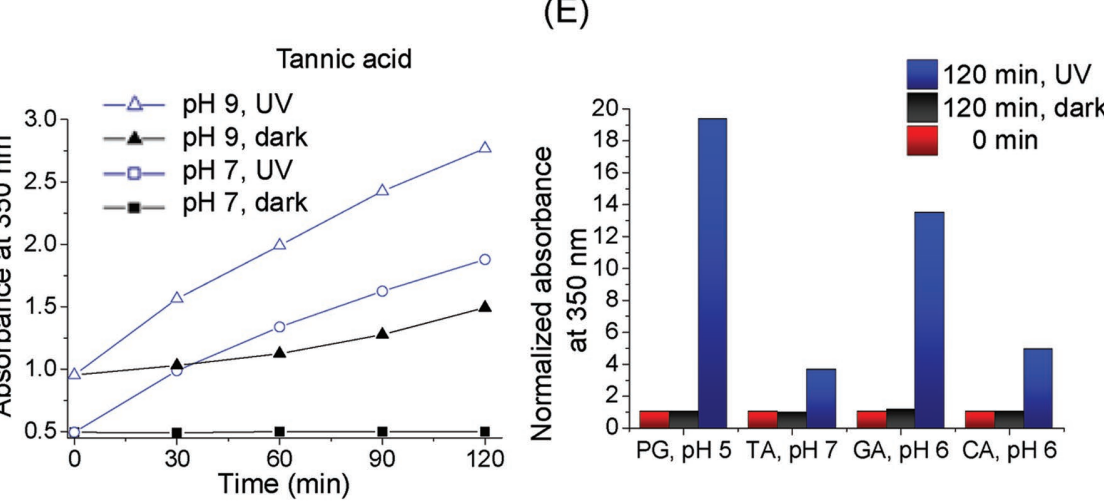

Figure 2. UV irradiation of plant-derived phenolics leads to a change of color and increase in the absorbance of solutions. The concentration of plantderived phenolic compounds in each sample is $0.2 \mathrm{mg} \mathrm{mL}^{-1}$ in a corresponding buffer $\left(100 \times 10^{-3} \mathrm{M}\right)$. A) Photographs of the corresponding solutions after UV irradiation and in the dark. UV-vis spectra of B) PG solution in acetate buffer at pH 5.0 and C) TA in phosphate buffer at pH 7.0 stored in the dark (left) and after UV irradiation (right) measured at different time intervals. D) Absorbance of the PG (left) and TA (right) solutions at $350 \mathrm{~nm}$ as a function of time and $\mathrm{pH}$. E) Normalized UV absorbance of PG, TA, GA, and CA solutions at $350 \mathrm{~nm}$ at $0 \mathrm{~h}$, before and after $2 \mathrm{~h}$ of UV irradiation. A significant increase in UV absorbance is observed for phenolics solution after $2 \mathrm{~h}$ UV irradiation.

19.3, 3.6, 13.5, and 4.9, respectively (Figure 2E). However, UV absorbance of these samples stored in the dark for $120 \mathrm{~min}$ remained the same (Figure 2D,E). An increase in the kinetics of phenolics oxidation was observed by increasing the $\mathrm{pH}$ from 5.0 to 10.0 (Figures S1-S8, Supporting Information). Although increasing the $\mathrm{pH}$ of solutions speeds up the oxidation and associated increase of absorbance of the phenolic solutions even in the dark, UV irradiation accelerates this process even more (Figure 2D,E; Figure S9, Supporting Information, for other phenolics). Darkening of the solution and increase of UV absorbance at $350 \mathrm{~nm}$ in oxidative condition is usually associated with higher molecular weight species and polymerization of phenolics. ${ }^{[10 \mathrm{~d}, 12 \mathrm{c}]}$
In order to prove that UV irradiation triggers polymerization of phenolic compounds, we performed ESI-MS analysis of PG solutions ( $\mathrm{pH}$ 5.0) either subjected to UV or kept in the dark for $2 \mathrm{~h}$ (Figure 3 ). Increase in UV-vis absorbance at $350 \mathrm{~nm}$ of plant phenolics under basic conditions was attributed to quinone formation. ${ }^{[8,10 \mathrm{~d}]}$ However, formation of higher molecular weight species through oxidation of catechol and gallol moieties in plant phenolics was also reported. ${ }^{[27]}$ Our ESI-MS analysis clearly shows the presence of higher molecular-weight species following UV irradiation of PG solution, while no oligomers or polymers were detected in the case of nonirradiated samples (Figure 3A). The repeating unit of the observed oligomer is $105.96 \mathrm{~m} / z$, which corresponds to the monomeric unit and 
(A)

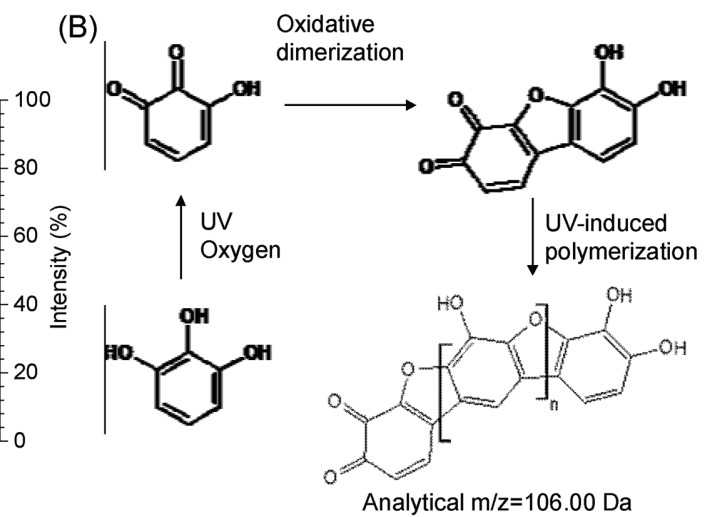

(C)
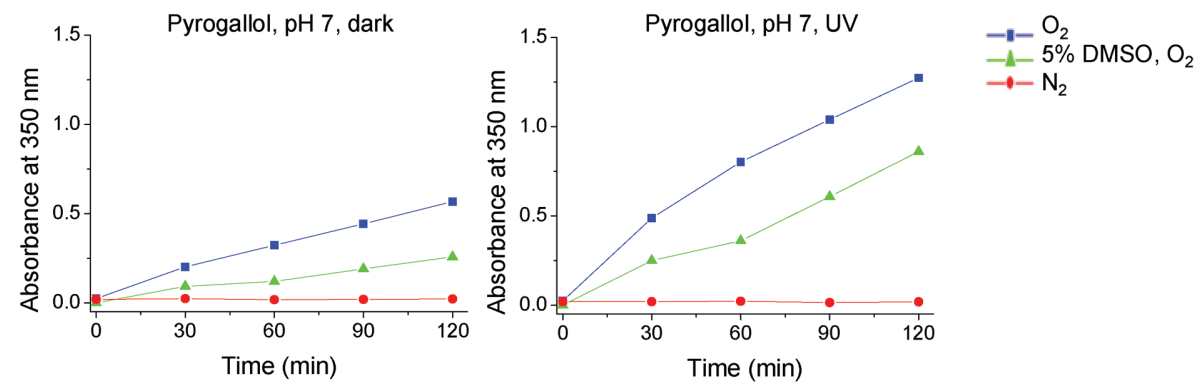

(D)
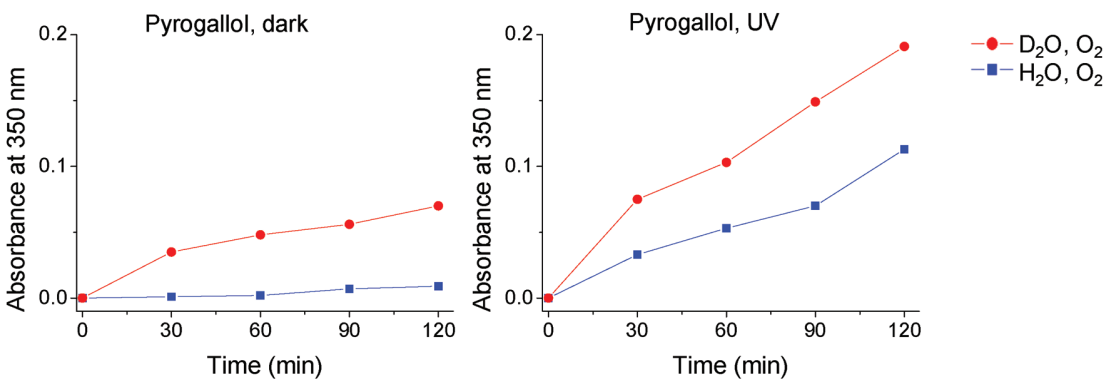

Figure 3. A) ESI-MS spectra (positive mode, data acquired for $30 \mathrm{~s}$ ) of PG solution in acetate buffer at $\mathrm{pH} 5.0$ in dark and after UV irradiation for $2 \mathrm{~h}$. ESI-MS spectra of UV-irradiated PG polymerization solution clearly shows presence of higher molecular weight species. B) Schematic representation of UV-induced polymerization of PG. C) UV absorbance at $350 \mathrm{~nm}$ of PG solution in phosphate buffer at pH 7.0 (blue), with addition of 5 vol\% DMSO (green), and after deoxygenation with $\mathrm{N}_{2}$ (red) for solutions kept in dark (left) and under UV irradiation (right). D) UV absorbance of PG solution at $350 \mathrm{~nm}$ in deionized water (blue) and deuterium oxide (red) media stored in dark (left) and under UV irradiation (right).

oligomer structures depicted in Figure 3B. The same repeating unit was previously proposed for the oligomerization of PG under alkaline conditions. ${ }^{[27 a]}$

Having shown that UV irradiation can accelerate polymerization of the phenolic compounds, additional experiments were performed in order to investigate the mechanistic aspects of the UV-induced transformation. It is known that reactive oxygen species (ROS), including singlet oxygen $\left({ }^{1} \mathrm{O}_{2}\right)$, superoxide radicals $\left(\mathrm{O}_{2}^{-\cdot}\right)$, or highly reactive hydroxyl radicals $\left({ }^{\circ} \mathrm{OH}\right)$ can be generated under UV irradiation even in the presence of traces of $\mathrm{O}_{2} \cdot{ }^{[28]}$ Previously, we reported the importance of ROS in the case of UV-induced dopamine polymerization. ${ }^{[9]}$ On the other hand, plant phenolics have also been known for their antioxidant characteristics and ability to react with ROS. ${ }^{[14,15,17,29]}$

In order to investigate the role of oxygen and ROS in the UVinduced polymerization of plant phenolic compounds, several experiments were performed (Figure 3C,D; Figures S10-S13, Supporting Information). First, PG solution at $\mathrm{pH} 7.0$ was deoxygenated by passing nitrogen for $30 \mathrm{~min}$, followed by UV irradiation. As shown in Figure 3C, the UV-absorbance of the deoxygenated solution at $350 \mathrm{~nm}$ did not increase even after 2 $\mathrm{h}$ of continuous UV irradiation, contrary to the same sample in the presence of oxygen (Figure 3C). Interestingly, the same inhibition of the polymerization was observed when the PG solution at $\mathrm{pH} 7.0$ stored in the dark was deoxygenated (Figure 3C). In another experiment, 5 vol\% of dimethyl sulfoxide (DMSO) was added to the reaction solution. DMSO is known to be a hydroxyl radical scavenger. ${ }^{[30]}$ UV irradiation of the DMSOcontaining PG solution did result in a smaller increase of the absorption at $350 \mathrm{~nm}$ in comparison to the control without DMSO (Figure 3C). The same slight inhibition of polymerization in the presence of DMSO was observed in the case of solutions stored in the dark (Figure 3C). On the other hand, deuterium oxide is known to be a singlet oxygen half-life prolonger. ${ }^{[31]}$ Changing the medium from deionized (DI) water to deuterium oxide increased the UV absorption of PG solution 
stored in dark and UV-irradiated PG solution (Figure 3D). These observations suggest that UV-triggered polymerization of plant phenolics requires ROS and oxygen. Increasing ROS concentration can increase the rate of the UV-induced polymerization of phenolics, while quenching ROS and deoxygenation of the solution lead to the inhibition of polymerization.

Antioxidant properties and electrochemical behavior of plant phenolics depend on their chemical structure and experimental conditions. ${ }^{[14,17,32]}$ We investigated the effect of UV irradiation on electrochemical oxidation of plant phenolic compounds using cyclic voltammetry (Figure 4; Figures S14-S21, Supporting Information). PG as well as GA display two anodic peaks corresponding to the oxidation to the semi-quinone and the subsequent oxidation to the quinone form. ${ }^{[33]}$ Monitoring of PG in acetate buffer at $\mathrm{pH} 5.0$ incubated for $2 \mathrm{~h}$ in dark environment indicates a slight change in peak current values (Figure 4A). However, continuous UV irradiation for $2 \mathrm{~h}$ enhanced the oxidation rate of PG and decreased the peak current values by $20 \%$ (Figure 4B). Significant decrease in peak current is due to consumption of PG after UV irradiation. UV irradiation also increased the rate of oxidation of $\mathrm{PG}$ in basic $\mathrm{pH}$ as indicated by more reduction of peak currents after UV irradiation compared to solutions stored in dark (Figures S14 and S15, Supporting Information).

The CV also confirmed irreversible oxidation of TA (Figures S18 and S19, Supporting Information). However, in contrast to PG and GA, the anodic peak currents for TA remain mostly constant over time independently of illumination and $\mathrm{pH}$ value. TA is composed of 10 quinone moieties, which may predominantly undergo intramolecular reactions. In this case, the total concentration and molecular weights (or diffusion coefficient) of TA and its reaction products would not change significantly, thereby explaining the mostly unchanged oxidation peak current. Nevertheless, although CV is not sensitive enough to quantitatively monitor the minor fluctuation in peak currents, intermolecular reaction leading to polymeric compounds in analogy to the behavior of GA and PG are also expected to take place.

Caffeic acid in contrast to the other three phenolic compounds displays a reductive peak in addition to the oxidation peak in the CV at low pH values (Figures S20 and S21, Supporting Information). The electrochemical response is attributed to a one-electron oxidation to the semiquinone form followed by a second oxidation to the quinone. Both oxidized forms undergo follow up irreversible chemical reactions ${ }^{[34]}$ whereby the semiquinone reaction involves dimerization. ${ }^{[35]}$ In more basic media ( $\mathrm{pH}>8$ ), an increasingly irreversible behavior suggests that the oxidation of CA is followed by a polymerization process. ${ }^{[36]}$ This is confirmed by the decrease in peak current over time indicating the consumption of the monomeric compounds. The $\pi$ conjugated systems in CA also induces a different behavior under illumination. While PG, GA, and TA undergo light accelerated oxidative polymerization, caffeic acid first undergoes a light-induced trans-cis-isomerization followed by intramolecular cyclization. ${ }^{[37]}$ The CVs confirm this behavior with the appearance of a new oxidation wave upon illumination in acidic media. The decrease of the reduction waves reveals the consumption of the caffeic acid (both cis and trans forms) over prolonged illumination times. Observations from cyclic voltammetry for all phenolic compounds are in agreement with UV-vis spectroscopic data.

Plant-derived phenolic compounds are able to form functional nanocoatings on various substrates. ${ }^{[7 \mathrm{~b}, 10 \mathrm{c}, \mathrm{d}, 11 \mathrm{a}, \mathrm{d}, \mathrm{f}, 12,38]}$ Messersmith and co-workers ${ }^{[12 c]}$ showed that even phenolic crude extracts from red wine, cacao bean, and green tea could form coatings on different materials. ${ }^{[\mathrm{bb}]}$ Jeon et al. ${ }^{[10 \mathrm{~d}]}$ reported the use of laccase enzyme to catalyze polymerization of dopamine, catechin/catechol, ferulic acid/catechol, catechin/syringic acid, and tannic acid/catechol to form functional coatings. Ejima et al. ${ }^{[11 f]}$ introduced the use of multivalent coordination of TA and Fe(III) for surface coatings of particulate and planar substrates. All mentioned examples utilized the ability of plant phenolic compounds to spontaneously polymerize either under basic conditions, ${ }^{[7 b, 12]}$ in the presence of metal ions ${ }^{[11]}$ or enzymes. ${ }^{[10 \mathrm{c}, \mathrm{d}, 38 \mathrm{a}, 39]}$

In order to investigate the ability to create functional phenolic nanocoatings using UV light as a trigger, polar and nonpolar polymeric substrates (poly(tetrafluoroethylene) (PTFE), poly(ethylene) (PE), poly(methyl methacrylate) (PMMA)) were immersed into a PG solution $\left(10 \times 10^{-3} \mathrm{M}, \mathrm{pH} 5.0\right)$ and irradiated with UV light for $2 \mathrm{~h}$. Formation of a PG layer onto the surface was visualized by immersing the substrate in $\mathrm{AgNO}_{3}$ aqueous solution (Figure 5). Substrates modified by PG under UV irradiation turned darker due to the reductive effect of the polyphenol nanocoating and the formation of metallic silver nanoparticles from silver nitrate (Figure $5 \mathrm{~A}) \cdot{ }^{[12 \mathrm{c}]}$ The color of
(A)

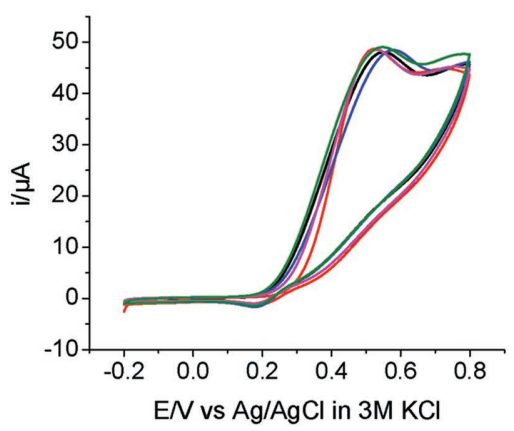

Pyrogallol, pH 5, UV

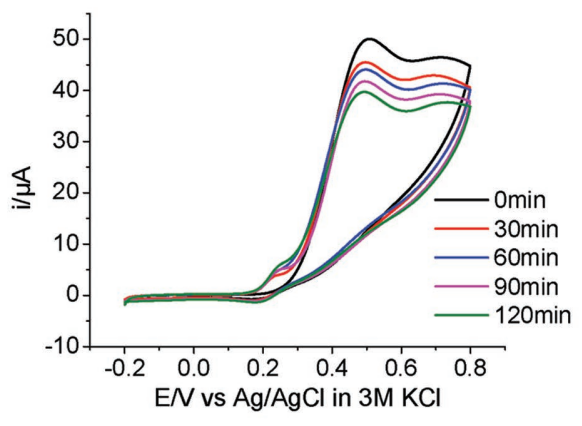

(B)

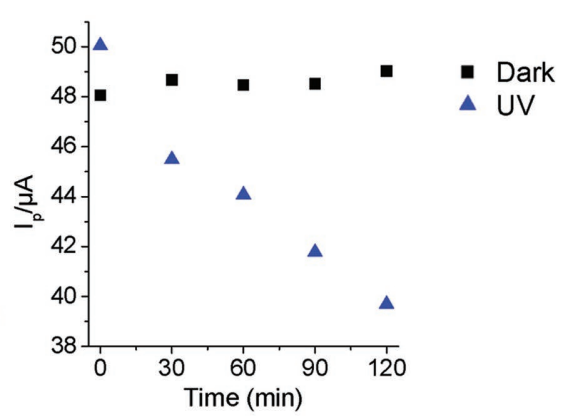

Figure 4. Monitoring of PG by cyclic voltammetry (CV). Cyclic voltammograms of PG in acetate buffer at $\mathrm{pH} 5.0 \mathrm{~A}$ ) stored for $2 \mathrm{~h}$ in dark (left) and under UV irradiation (right) versus time. B) Peak currents over time for PG in acetate buffer $\mathrm{pH} 5.0$ stored in dark or under UV irradiation for $2 \mathrm{~h}$. All $\mathrm{CVs}$ were measured in $100 \times 10^{-3} \mathrm{M}$ buffer at a scan rate of $100 \mathrm{mV} \mathrm{s}^{-1}$ at glassy carbon electrodes with $1.58 \times 10^{-3} \mathrm{M}$ concentration of PG. 
(A)

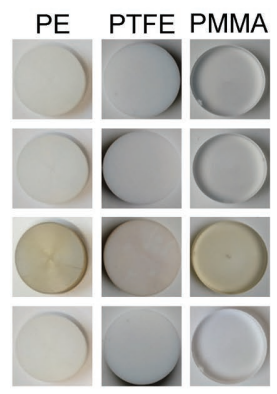

(C)

Unmodified

Pyrogallol (pH 5.0)+UV

Pyrogallol+UV+Ag

Unmodified $+\mathrm{Ag}^{+}$

(B)
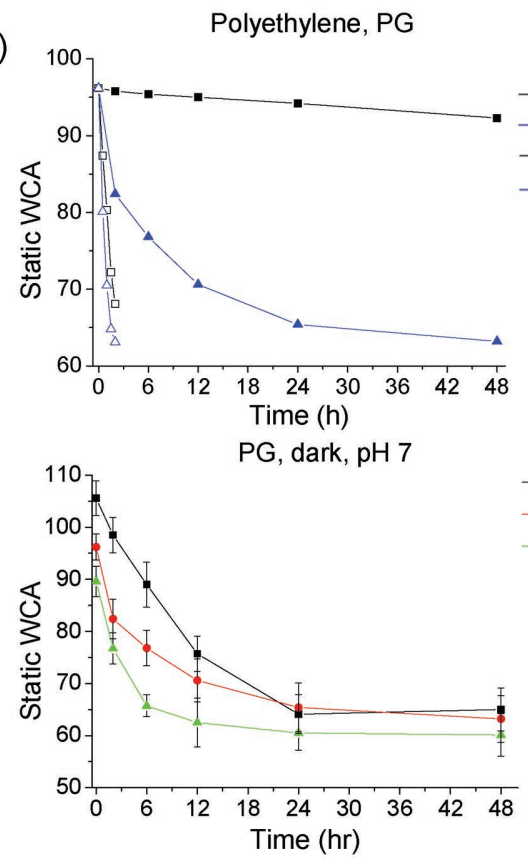

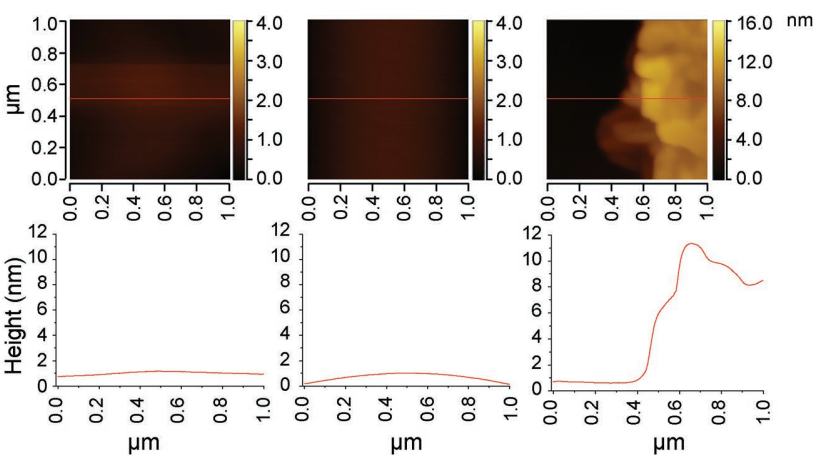

(D)

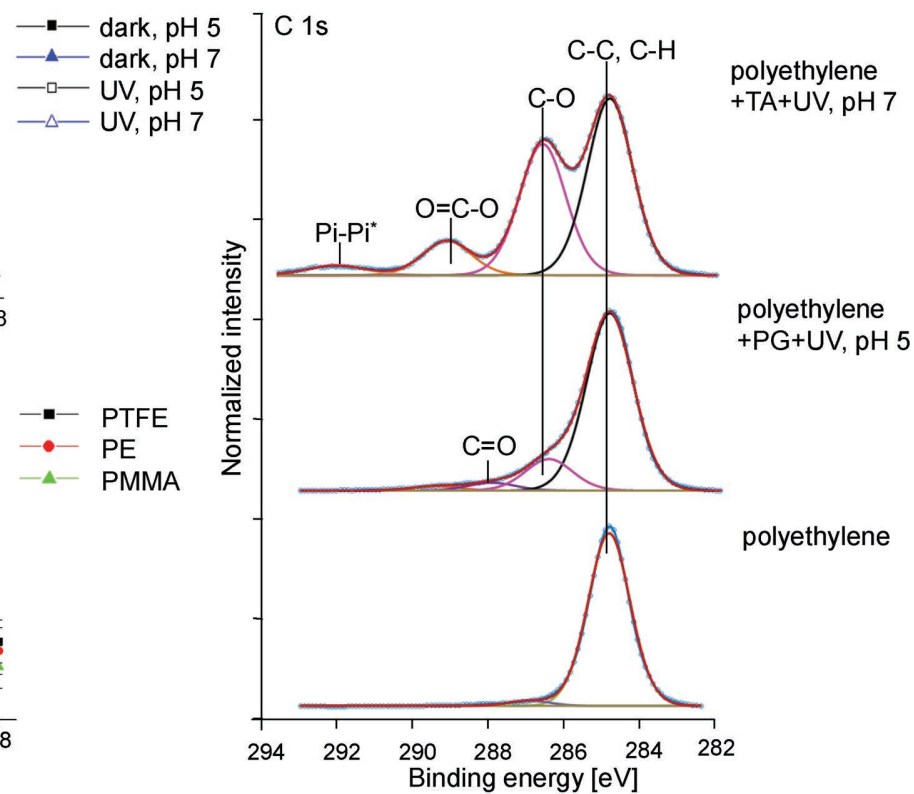

Figure 5. Deposition of a plant-derived phenolic coating on PE, PMMA, and PFTE substrates. A) Photographs of unmodified, PG-modified, and $\mathrm{AgNO}_{3}$-treated substrates. B) Decrease of the static WCA over time for PE substrate after immersion in $10 \times 10^{-3} \mathrm{M}$ PG solution (acetate buffer at pH 5.0, phosphate buffer at $\mathrm{pH}$ 7.0) stored in dark environment and UV-irradiated substrates for $2 \mathrm{~h}$ (top, Figure S22C with error bar, Supporting Information). Static WCA reaches to a substrates independent value after immersion of PTFE, PE, and PMMA substrates in $10 \times 10^{-3} \mathrm{M}$ PG solution (bottom, phosphate buffer at pH 7.0) for 48 h. C) AFM image of bare silicon (left), silicone immersed in PG solution in dark (acetate buffer at pH 5.0) (middle), and PG-modified silicon wafer (right) gently scratched by tweezers. Corresponding diagram of line scan of each sample through the red line is shown below the image. D) C 1s XP spectra of polyethylene before and after modification with a coating based on PG (acetate buffer at pH 5.0, $2 \mathrm{~h}$ UV irradiation) and TA (phosphate buffer at $\mathrm{pH} \mathrm{7.0,2} \mathrm{h}$ UV irradiation). All spectra are normalized to the highest intensity.

unmodified substrates and substrates dipped in PG solution stored in dark remained unchanged (Figure 5A).

The acceleration of deposition of plant phenolics under UV irradiation is also confirmed by water contact angle (WCA) measurements (Figure 5B). Thus, the static WCA of PE substrate immersed in PG solution dropped from $96.2^{\circ}$ to $68.1^{\circ}$ after $2 \mathrm{~h}$ of UV irradiation at $\mathrm{pH} 5.0$, while the static WCA on the same substrate kept in dark did not change after $2 \mathrm{~h}$ and decreased only to $92.3^{\circ}$ after $48 \mathrm{~h}$. It is known that basic $\mathrm{pH}$ accelerates polymerization and deposition of PG. However, even at pH 7.0 static WCA of PE decreased only to $82.4^{\circ}$ after 2 and $24 \mathrm{~h}$ of incubation was required to reach the lowest static WCA $63.1^{\circ}$ achievable at $\mathrm{pH}$ 7.0. Similar static WCAs were measured on PTFE and PMMA substrates after $48 \mathrm{~h}$ of incubation of the surfaces with PG solution at $\mathrm{pH} 7.0$ in the dark (Figure 5B), confirming homogeneous deposition of a
PG layer independent of the substrate. UV irradiation of the PE surface for $2 \mathrm{~h}$ at $\mathrm{pH} 5.0$ without addition of PG did not result in a decrease of the static WCA (Figure S22A, Supporting Information). A Aimilar trend was observed for other plant phenolics studied (Figure S22B, Supporting Information).

Messersmith and co-workers reported a thickness of 19 and $71.6 \mathrm{~nm}$ for a PG-based layer on $\mathrm{TiO}_{2}$ and polycarbonate surfaces, respectively. This measurement was performed after $24 \mathrm{~h}$ of incubation in the solution at $\mathrm{pH} 7{ }^{[7 \mathrm{~b}]}$ Jeon et al. reported thickness of dual-monomer systems of plant phenolics on PET substrates ranging between 90 and $200 \mathrm{~nm}$ after $15 \mathrm{~h}$ of dipping in polymerization media. ${ }^{[10 \mathrm{~d}]}$ Ejima et al. reported a thickness of $\mathrm{Fe}(\mathrm{III})$-TA films on polystyrene templates and gold substrates around 2 and $10 \mathrm{~nm}$, respectively, within one deposition cycle. ${ }^{[11 f]}$ We demonstrate that no polymer deposition happens after $2 \mathrm{~h}$ incubation of a silicon 
wafer in PG solution in acetate buffer at $\mathrm{pH}$ 5.0, while a $10 \pm 2 \mathrm{~nm}$ thick polymer layer as measured by atomic force microscopy (AFM) is formed after $2 \mathrm{~h}$ UV irradiation (Figure $5 \mathrm{C}$ ). The root mean square deviation of the roughness profile of the silicon wafer incubated for $2 \mathrm{~h}$ in the dark (acetate buffer, $\mathrm{pH}$ 5.0) changed from $0.128 \pm$ 0.020 to $1.195 \pm 0.288 \mathrm{~nm}$ for the silicon substrate immersed in PG solution (acetate buffer, pH 5.0) and irradiated with UV for $2 \mathrm{~h}$.

In order to investigate the surface chemistry of plant-derived phenolics coated substrates, X-ray photoelectron spectroscopy (XPS) measurements of coated PE substrates immersed in PG and TA solutions (acetate buffer at pH 5.0 and phosphate buffer at $\mathrm{pH} 7.0$, respectively) after $2 \mathrm{~h}$ of UV irradiation were conducted. PE substrate immersed in the same buffer after $2 \mathrm{~h}$ of UV irradiation was used as the reference substrate. As expected, the C 1s XP spectrum from $\mathrm{PE}$ shows one main peak at $285.0 \mathrm{eV}$ attributed to $\mathrm{C}-\mathrm{C}, \mathrm{C}-\mathrm{H}$ groups (Figure 5D). A further peak at $286.6 \mathrm{eV}$ in the C 1s XP spectra of substrates coated with PG and TA appears, corresponding to the presence of $\mathrm{C}-\mathrm{O}$ groups and proving clearly the deposition of a thin layer of phenolics on the surface. ${ }^{[40]}$ Furthermore, the carboxyl group present in TA can be clearly detected at $289.0 \mathrm{eV}$. In addition, the higher intensity ratio $\mathrm{C}-\mathrm{O} /(\mathrm{C}-\mathrm{C}, \mathrm{C}-\mathrm{H})$ for the $\mathrm{TA}$ coating (0.7) as for PG deposition (less than 0.2 ) leads to conclude that the TA film is thicker than that of the PG film.

The ability to use UV light to induce polymerization of various plant-derived phenolic compounds opens the possibility for both spatial and temporal control of the deposition of phenolic nanocoatings on different surfaces. In order to demonstrate this, we irradiated a PTFE substrate covered either with a $125 \mu \mathrm{m}$ layer of $10 \times 10^{-3}$ M PG solution (acetate buffer, $\mathrm{pH}$ 5.0) or TA solution (phosphate buffer, $\mathrm{pH}$ 7.0) with UV light for $1 \mathrm{~h}$ through a quartz photomask (Figure S23A, Supporting Information). A clear pattern of silver particles or fluorescence was formed on the surface after immersing the substrates either in a silver nitrate aqueous solution or rhodaminethiol solution, ${ }^{[41]}$ respectively (Figure 6A). The formation of a pattern based on PG on PTFE followed by modification with silver particles was confirmed by time-of-flight secondary ion mass spectrometry (ToF-SIMS) (Figure 6B).

To demonstrate the unique advantages of UV-assisted polymerization and deposition of plant phenolic compounds, a gradient pattern of PG was formed on the poly(2-hydroxyethyl

\section{(D)}

(A)

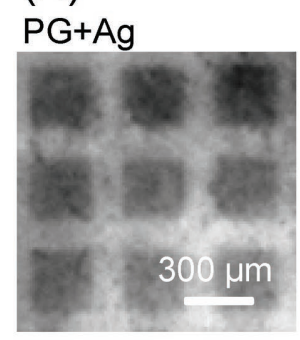

$\mathrm{TA}+\mathrm{Ag}$

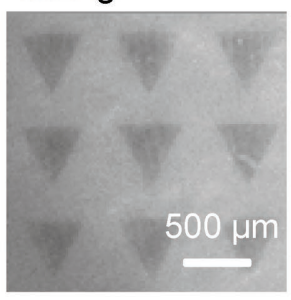

(C)

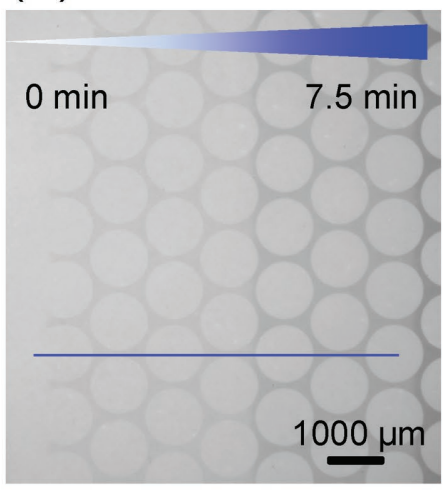

(B)
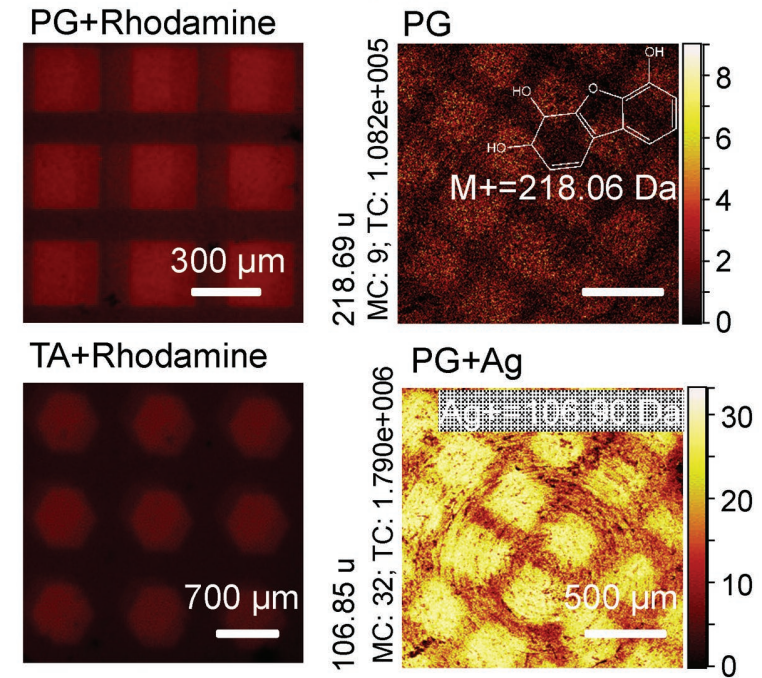
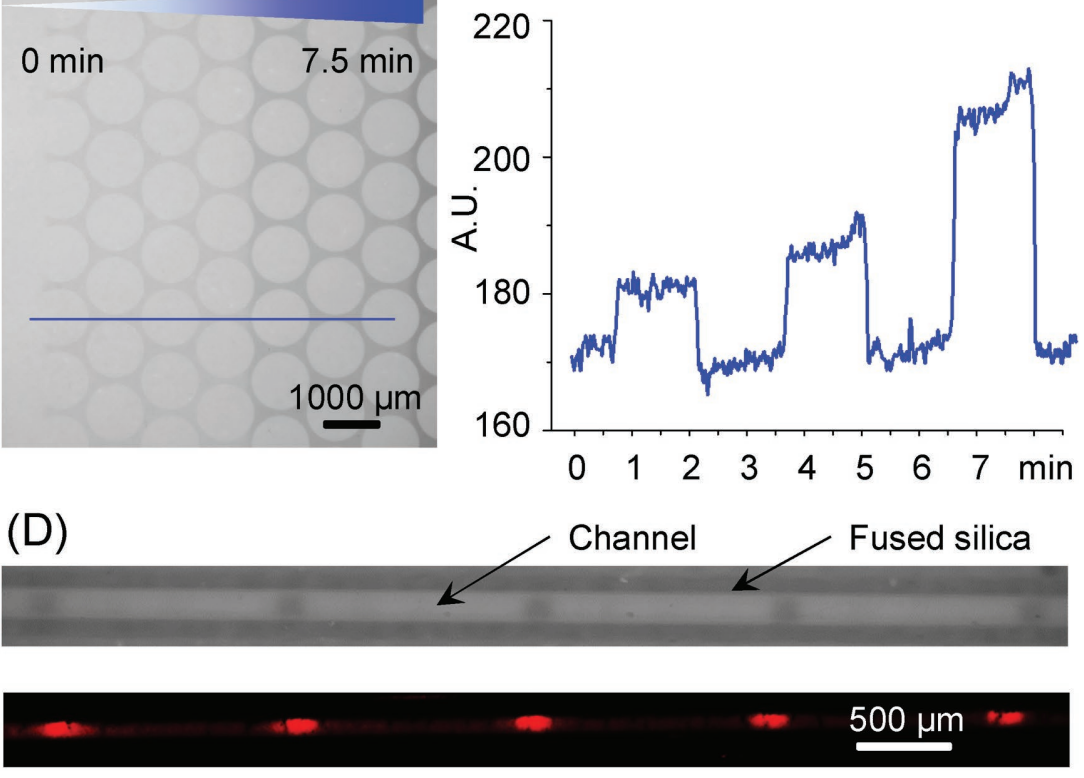

Figure 6. A) Bright-field microscopy image of a silver particle pattern produced on surface of phenolic pattern based on PG (UV, acetate buffer at $\mathrm{pH}$ 5.0) or TA (UV, phosphate buffer at $\mathrm{pH}$ 7.0) after immersing the substrate in silver nitrate solution for $48 \mathrm{~h}$. Red fluorescence pattern formed by treatment of the phenolic patterns with a rhodamine-thiol solution. B) ToFSIMS ion intensity map of a phenolic square pattern (PG, UV, acetate buffer at $\mathrm{pH} 5.0$ ) on PTFE substrate produced by photopatterning (top), and silver ion intensity map of modified pattern with silver nitrate aqueous solution for $48 \mathrm{~h}$ (bottom). C) Polyphenolic gradient pattern formed by UV irradiation of a poly(HEMA-EDMA) surface in the presence of a PG solution ( $0.01 \mathrm{mg} \mathrm{mL}^{-1}, \mathrm{pH} 7.0$ ). The phenolic pattern was incubated for $48 \mathrm{~h}$ in a silver nitrate aqueous solution to obtain a pattern of silver particles. Corresponding gray value versus UV exposure time along the blue line is shown in the graph (right). D) Phenolic pattern inside a microfluidic capillary (inner diameter $100 \mu \mathrm{m}$ ). Fused silica capillary filled with a porous polymethacrylate was filled with a pyrogallol solution $\left(0.01 \mathrm{~g} \mathrm{~mL}^{-1}, \mathrm{pH} 7.0\right)$ and irradiated with UV light for $10 \mathrm{~min}$ through a photomask. A pattern of silver particles (top) and rhodamine dye (bottom) formed inside the capillary by corresponding postmodification of the polyphenol pattern.

methacrylate)-co-(ethylene dimethacrylate) (poly(HEMAEDMA) surface. In order to create a gradient pattern, PG solution $\left(0.01 \mathrm{mg} \mathrm{mL}^{-1}, \mathrm{pH} 7.0\right)$ was added to the surface, covered 
by a photomask and by a UV opaque cover. By moving the cover gradually, different regions of the surface were exposed to UV irradiation from 0.0 to $7.5 \mathrm{~min}$, generating a gradient of density of the polyphenol coating (Figure 6C; Figure S23B, Supporting Information). To further prove the versatility of this technique, we used this approach to make a pattern of a polyphenol coating inside a microfluidic channel. PG solution $\left(0.01 \mathrm{mg} \mathrm{mL}^{-1}, \mathrm{pH}\right.$ 7.0) was injected into a capillary filled with porous poly(HEMAEDMA) with a syringe and UV irradiated for $10 \mathrm{~min}$ through a photomask (Figure S24, Supporting Information). Patterned polyphenol coating inside the capillary was further functionalized with silver particles or Rhodamine dye (Figure 6D). The observed patterns confirm that multifunctional polyphenolic coating, patterns, and gradients can be formed on flat surfaces and on curved interfaces of closed microfluidic channels.

Natural plant phenolic compounds have gained lots of attention due to their antioxidant, antimicrobial, anticancer, and antiinflammatory properties. ${ }^{[14,17]}$ Plant-derived phenolic compounds are found in various types of beverages and food. ${ }^{[14,15,17,26,42]}$ Thus, several groups investigated the possibility to create nanocoatings using cocktails of phenolics directly extracted from different beverages. ${ }^{[12 c, 43]}$ The advantage of using such mixtures is their availability and low costs. Here we show that UV light can also accelerate the polymerization and deposition of phenolic cocktails present in tea, coffee, or wine. Figure S25 (Supporting Information) shows the photographs of glass substrate covered with tea, coffee, or red wine, after $1 \mathrm{~h}$ in the dark and under UV irradiation. The visualization of the coating was performed using a silver nitrate solution. Corresponding UV-vis transmittance spectra are depicted in Figure S25B (Supporting Information). The decrease of transmittance of the coatings after UV irradiation indicates the acceleration of the polymerization and deposition of the phenolics found in these beverages. Formation of dark layer of silver particles on the glass surface modified with phenolic compounds existing in tea, coffee, and wine after immersion in silver nitrate aqueous solution increased darkness of the glass slides. However, transmittance of glass slides after immersion in tea, coffee, and wine followed by immersion in silver nitrate aqueous solution did not change.

\section{Conclusions}

In conclusion, we demonstrated for the first time that UV irradiation significantly accelerates both polymerization and deposition of various plant-derived phenolic compounds. The kinetics of oxidative polymerization of plant phenolics depends on the presence of oxygen, $\mathrm{ROS}$, and $\mathrm{pH}$ of the solution. The $\mathrm{pH}$ effect varies for different phenolic compounds. We show that increasing ROS concentration in the presence of oxygen or changing the aqueous medium to deuterium oxide solution accelerates the oligomerization of phenolic compounds under UV light, while deoxygenation or addition of ROS scavengers can retard the polymerization reaction. This process is general and can be applied to various plant-derived phenolics as demonstrated on pyrogallol, tannic, gallic, and caffeic acids as well as natural phenolic compounds present in tea, coffee, and wine. The UV-assisted polymerization and deposition of polyphenols opens the possibility to create patterns and gradients of multifunctional polyphenolic coatings on curved surfaces and inside microfluidic channels in a substrate-independent way. Taking into account the huge diversity, availability, and low cost of plant-derived phenolic compounds, this method opens unique opportunities for the spatial and temporal control in the formation of functional plant-derived phenolic nanocoatings and their micropatterns.

\section{Experimental Section}

Materials: TA (1701.19 $\mathrm{g} \mathrm{mol}^{-1}$, solid brown powder) was purchased from Sigma-Aldrich (Germany). All other (poly)phenols analogs, including pyrogallol $\left(126.11 \mathrm{~g} \mathrm{~mol}^{-1}\right.$, solid white powder), CA (170.12 $\mathrm{g} \mathrm{mol}^{-1}$, solid yellow powder), GA (180.16 $\mathrm{g} \mathrm{mol}^{-1}$, solid powder) were purchased from Sigma (Germany). 2-Hydroxyethyl methacrylate (HEMA), ethylene dimethacrylate (EDMA) were purchased from SigmaAldrich (Germany).

PTFE, PMMA, PE, glass slides, and silicon wafer substrates were cleaned by sonication in DI water, 2-propanol, and $0.1 \mathrm{M} \mathrm{HCl}$ for $10 \mathrm{~min}$, washed with DI water, and dried with nitrogen gas. PMMA, PTFE, and PE substrates were kindly provided by Institute of Toxicology and Genetics. Silver nitrate and all the other chemicals were purchased from SigmaAldrich (Germany) and used without further purification. High-purity DI water with a resistivity of $18.2 \mathrm{M} \Omega \mathrm{cm}$ was obtained from an inline Millipore water purification system. Acetone and the other solvents were obtained from Merck KGaA (Germany). Flexible UV-transparent fused silica capillary tubing (TSU100375 model) was purchased from Polymicro Technologies (Germany)

Methods: All buffers were made at $100 \times 10^{-3} \mathrm{M}$ concentration. The following buffers were used: acetate $(\mathrm{pH} \mathrm{4,} \mathrm{pH} \mathrm{5,} \mathrm{pH} 6)$, phosphate $(\mathrm{pH} 7, \mathrm{pH} 8)$, and carbonate-bicarbonate $(\mathrm{pH} 9, \mathrm{pH} 10)$. Sodium chloride $\left(600 \times 10^{-3} \mathrm{M}\right)$ was added to buffers in deposition and patterning process.

UV-Irradiation of Phenolics Solutions: An OAI model 30 deep-UV collimated light source (San Jose, CA, USA) fitted with a $500 \mathrm{~W}$ $\mathrm{HgXe}$ lamp was used for UV irradiation. The lamp was calibrated to $10 \mathrm{~mW} \mathrm{~cm} \mathrm{~cm}^{-2}$ at $260 \mathrm{~nm}$ with the OAI $306 \mathrm{UV}$ power meter. Reaction solutions were transferred into a glass vial and irradiated under UV lamp for $2 \mathrm{~h}$ (stirred at room temperature, ambient atmosphere).

UV-Vis Absorption Experiments: Phenolic compound solution $\left(0.2 \mathrm{mg} \mathrm{mL} \mathrm{m}^{-1}\right)$ in buffers at different $\mathrm{pH}\left(100 \times 10^{-3} \mathrm{M}\right)$ were stored in dark environment (dark samples) and were irradiated under UV (UV samples) for $2 \mathrm{~h}$. The UV-vis absorbance $(300-900 \mathrm{~nm})$ of the dark and UV samples measured at different time points $(0,30$, 60,90 , and $120 \mathrm{~min}$, buffer as the reference) using a Biotek Epoch 2 spectrophotometer.

Deoxygenated Solutions: In order to keep the low oxygen containing conditions, nitrogen gas was passed through the PG solution for $30 \mathrm{~min}$ in a quartz vial equipped with septum. After purging nitrogen solution, the vial was irradiated for $2 \mathrm{~h}$ with the same UV light used for other solutions. Same procedure was used to prepare solution in dark environment.

Samples Containing 5 vol\% DMSO: Buffer solutions $(\mathrm{pH} 7.0$ nonpurged solutions were used) containing 5 vol\% DMSO were added to the PG solutions $\left(0.2 \mathrm{mg} \mathrm{mL}^{-1}\right)$ and samples were irradiated with UV or kept in the dark for $2 \mathrm{~h}$. UV-vis absorption spectra were recorded at 0 , $30,60,90$, and $120 \mathrm{~min}$.

UV-Vis Measurement in DI Water and Deuterium Oxide Medium: PG solution $\left(0.2 \mathrm{mg} \mathrm{mL}^{-1}\right)$ in DI water was subjected to UV irradiation or kept in dark environment for $2 \mathrm{~h}$, and UV-vis absorption spectra were recorded at $0,30,60,90$, and $120 \mathrm{~min}$. Same procedure was used to measure UV-vis spectra of PG solution $\left(0.2 \mathrm{mg} \mathrm{mL}^{-1}\right)$ in deuterium oxide.

Electrochemistry: All electrochemical measurements were performed with a Reference 600 potentiostat (Gamry Instruments, Warminster, PA) in a three-electrode cell with a coiled Pt wire as the counterelectrode, an 
$\mathrm{Ag} / \mathrm{AgCl}(3 \mathrm{M} \mathrm{KCl})$ reference electrode and a glassy carbon disk electrode ( $3 \mathrm{~mm}$ in diameter) was employed as a working electrode. The phenolic compounds $\left(1.58 \times 10^{-3} \mathrm{M}\right)$ were dissolved in buffer $\left(100 \times 10^{-3} \mathrm{M}\right)$ at different $\mathrm{pH}$ values (vide supra). Cyclic voltammograms were scanned from -0.2 to $1 \mathrm{~V}$ for gallic acid and -0.2 to $0.8 \mathrm{~V}$ for the other phenolic compounds at a scan rate of $100 \mathrm{mV} \mathrm{s}^{-1}$. The glassy carbon electrode was polished before each cycle with $0.3 \mu \mathrm{m}$ alumina slurry and rinsed thoroughly with $\mathrm{DI}$ water to remove adsorbed polymeric species resulting from the previous measurements. A neoLab-UV Inspection Lamp Type 6 with $14 \mathrm{~mW} \mathrm{~cm} \mathrm{~cm}^{-2}$ was used for UV irradiation and positioned at a distance of $0.5 \mathrm{~cm}$ of a quartz cuvette containing the solution of the phenolic compound. The cyclic voltammograms were recorded at different time points $(0,30,60,90$, and $120 \mathrm{~min})$.

Deposition of Phenolic Layer on Substrate: Clean substrates were immersed in buffered solutions of $10 \times 10^{-3} \mathrm{M}$ precursor for 2, 6, 12, 24, and $48 \mathrm{~h}$ in dark room at room temperature. Modified samples were then rinsed thoroughly with DI water and dried with nitrogen gas. Same conditions used to modify substrate with precursor under UV irradiation for $2 \mathrm{~h}$. Coatings were visualized by immersing samples in $10 \times 10^{-3} \mathrm{M} \mathrm{AgNO}_{3}$ for $48 \mathrm{~h}$, followed by rinsing thoroughly with DI water, and drying with $\mathrm{N}_{2}$ gas.

Photopatterning of Phenolics: For patterning on substrate, a photomask was fixed on top of the substrate. After filling the $10 \times 10^{-3} \mathrm{M}$ phenolic solution ( $\mathrm{pH} 5.0$ for PG and $\mathrm{pH} 7.0$ for TA), the sample was UV irradiated for $1 \mathrm{~h}$. Then photomask was removed and the sample was rinsed with $\mathrm{DI}$ water and dried with $\mathrm{N}_{2}$. For the secondary modification by $\mathrm{AgNO}_{3}$, the patterned substrates were immersed into a $10 \times 10^{-3} \mathrm{M}$ $\mathrm{AgNO}_{3}$ aqueous solution for $48 \mathrm{~h}$, followed by washing with DI water and drying with $\mathrm{N}_{2}$. For the secondary modification by Rhodamine-SH (Rhodamine B was modified with cysteamine as described in our previous report ${ }^{[4]}$ to yield a rhodamine-thiol shown in Scheme S1), the patterned substrates were immersed in a mixture containing $3 \mathrm{~mL}$ of DI water, $10 \mathrm{mg}$ of the dye, and $70 \mu \mathrm{L}$ of triethylamine for $24 \mathrm{~h}$, then the substrate was carefully washed with DI water and dried with $\mathrm{N}_{2}$.

Gradient Pattern: In order to make a polyphenolic gradient pattern, poly(HEMA-EDMA)-modified substrate (details of nanoporous poly(HEMA-EDMA) could be found in our previous report) ${ }^{[44]}$ was fed into the patterning setup described before, and filled with PG solution (0.01 mg mL-1, pH 7.0, phosphate buffer). A black cardboard cover was used to cover the photomask. To make a gradient pattern of polyphenol, different regions of the surface were exposed to UV light from 0.0 to 7.5 min by moving the cardboard gradually.

Patterning Inside a Capillary: First, capillaries were modified with porous poly(HEMA-EDMA). Briefly, capillaries were filled with a sodium hydroxide solution $\left(1 \mathrm{~mol} \mathrm{~L}^{-1}\right)$ for $1 \mathrm{~h}$, followed by rinsing with DI water, then filling with an $\mathrm{HCl}$ solution $\left(1 \mathrm{~mol} \mathrm{~L}^{-1}\right)$ for $30 \mathrm{~min}$, then washing with DI water and drying with pumping air inside the capillary. The activated glass surface was functionalized with 20 vol\% 3-(trimethoxysilyl)propyl methacrylate in ethanol for $30 \mathrm{~min}$ followed by washing with ethanol. The polymerization mixture (HEMA 24 wt\%, EDMA 16 wt\%, 1-decanol $45.5 \mathrm{wt} \%$, cyclohexanol $14.5 \mathrm{wt} \%$, 2,2-dimethoxy-2-phenylacetophenone 1 wt\% with respect to monomers) was injected into the modified capillary using a syringe. Capillary filled with the polymerization mixture was placed under the UV lamp and irradiated with UV light for $15 \mathrm{~min}$ (the lamp was calibrated to $10 \mathrm{~mW} \mathrm{~cm}{ }^{-2}$ at $260 \mathrm{~nm}$ with the OAI $306 \mathrm{UV}$ power meter) followed by washing with ethanol. Porous polymer was formed inside the capillary. In order to make a polyphenolic pattern inside the capillary, PG solution $(0.01 \mathrm{mg} \mathrm{mL}-1, \mathrm{pH} 7.0$, phosphate) was injected into the capillary using a syringe. Capillary filled with the PG solution was placed under a photomask and irradiated with UV light $\left(10 \mathrm{~mW} \mathrm{~cm}{ }^{-2}\right.$ at $\left.260 \mathrm{~nm}\right)$ for $10 \mathrm{~min}$ followed by washing with DI water and acetone. For secondary modification with silver particles and fluorescent dye, aqueous solution of silver nitrate $\left(10 \times 10^{-3} \mathrm{M}\right)$ or Rhodamine 110 chloride solution $\left(0.2 \mathrm{mg} \mathrm{mL}^{-1}\right.$ in $10 \times 10^{-3} \mathrm{M}$ phosphate buffer at $\mathrm{pH}$ 8.0) were injected into the capillaries and reacted overnight, followed by washing with DI water and acetone and drying with air.

Polymerization and Deposition of Phenolic Compounds Present in Tea, Coffee, and Wine: Green tea bags (TEEKANNE Grüner TEE) and $20 \mathrm{~g}$ coffee powder (Bellarom espresso coffee) were steeped for $10 \mathrm{~min}$ in
$100 \mathrm{~mL} \mathrm{DI}$ water at $80^{\circ} \mathrm{C}$ and left to be cooled to room temperature following by filtration with paper filter. $50 \mathrm{~mL}$ of tea infusion, coffee infusion, wine (VIÑA DEL ASADOR Rioja DOCa) transferred to petri dish, and a cleaned glass slide were dipped into beverages solution. After $1 \mathrm{~h}$ in dark environment or $1 \mathrm{~h}$ UV irradiation with the described setup, glass slides were rinsed with DI water. In order to visualize the phenolic coating, glass slides were placed in $10 \times 10^{-3} \mathrm{M} \mathrm{AgNO}_{3}$ aqueous solution for $48 \mathrm{~h}$ followed by rinsing with DI. Photographing and UV-vis spectroscopy of glass slides were performed before and after each step.

Characterization: UV-vis spectroscopy was performed with an Epoch 2 microplate spectrophotometer (BioTech). UV-vis transmittance of glass slides was measured with a Lambda 35 UV-vis Spectrometer (PerkinElmer). A UK 1115 digital camera from EHD imaging (Germany) was used to take images of the water droplet on the surface under ambient conditions. Image) software with a Dropsnake plugin was used to measure the static water contact angle. The bright-field and fluorescence images were taken using a Leica DFC360 microscope (Germany). Mass analysis was performed using an ESI-MS (Bruker ESI-TOF in INT, KIT)

XPS measurements were performed using a K-Alphat XPS spectrometer (ThermoFisher Scientific, East Grinstead, UK). Data acquisition and processing using the Thermo Avantage software is described elsewhere. ${ }^{[45]}$ All coatings were analyzed using a microfocused, monochromated Al K $\alpha$ X-ray source $(400 \mu \mathrm{m}$ spot size). The K-Alpha charge compensation system was employed during analysis, using electrons of $8 \mathrm{eV}$ energy and low-energy argon ions to prevent any localized charge buildup. The spectra were fitted with one or more Voigt profiles (BE uncertainty: $\pm 0.2 \mathrm{eV}$ ) and Scofield sensitivity factors were applied for quantification. ${ }^{[46]}$ All spectra were referenced to the $C$ is peak $(\mathrm{C}-\mathrm{C}, \mathrm{C}-\mathrm{H})$ at $285.0 \mathrm{eV}$ binding energy controlled by means of the wellknown photoelectron peaks of metallic $\mathrm{Cu}, \mathrm{Ag}$, and $\mathrm{Au}$, respectively.

The distributions of phenolic mass fragments and silver ions on the surface were investigated with ToF-SIMS (ION TOF Inc, Münster, Germany), IFG, KIT. Atomic force microscopy was performed on a Dimension Icon AFM (Bruker) in standard tapping mode in air, INT, KIT. Cantilevers used where of type HQ:NSC15/AI BS (MikroMasch) with a nominal force constant of $40 \mathrm{~N} \mathrm{~m}^{-1}$ and a resonance frequency of $325 \mathrm{kHz}$.

\section{Acknowledgements}

The research was supported by the ERC Starting Grant (ID 337077-DropCellArray) and the Helmholtz Association's Initiative and Networking Fund (Grant No. VH-NG-621). The K-Alpha+ instrument was financially supported by the Federal Ministry of Economics and Technology on the basis of a decision by the German Bundestag.

\section{Keywords}

photopatterning, plant phenolics, polyphenol nanocoating, surface modification, UV-induced polymerization

[1] Q. Ye, F. Zhou, W. M. Liu, Chem. Soc. Rev. 2011, 40, 4244.

[2] a) C. Zhang, Y. Ou, W. X. Lei, L. S. Wan, J. Ji, Z. K. Xu, Angew. Chem., Int. Ed. Engl. 2016, 55, 3054; b) D. Perrot, C. Croutxe-Barghorn, 
X. Allonas, Polym. Chem. 2016, 7, 2635; c) D. B. Knorr, N. T. Tran, K. J. Gaskell, J. A. Orlicki, J. C. Woicik, C. Jaye, D. A. Fischer, J. L. Lenhart, Langmuir 2016, 32, 4370; d) Q. Wei, K. Achazi, H. Liebe, A. Schulz, P. L. M. Noeske, I. Grunwald, R. Haag, Angew. Chem., Int. Ed. Engl. 2014, 53, 11650; e) A. Rai, C. C. Perry, J. Mater. Chem. 2012, 22, 4790.

[3] a) X. Y. Zheng, F. Chen, J. X. Zhang, K. Y. Cai, J. Mater. Chem. $B$ 2016, 4, 2435; b) Y. Song, G. Ye, Y. X. Lu, J. Chen, J. C. Wang, K. Matyjaszewski, ACS Macro Lett. 2016, 5, 382; c) J. Saiz-Poseu, J. Sedo, B. Garcia, C. Benaiges, T. Parella, R. Alibes, J. Hernando, F. Busque, D. Ruiz-Molina, Adv. Mater. 2013, 25, 2066; d) D. Ling, W. Park, Y. I. Park, N. Lee, F. Li, C. Song, S. G. Yang, S. H. Choi, K. Na, T. Hyeon, Angew. Chem., Int. Ed. Engl. 2011, 50, 11360.

[4] a) F. Ponzio, J. Barthès, J. Bour, M. Michel, P. Bertani, J. Hemmerlé, M. d'Ischia, V. Ball, Chem. Mater. 2016, 28, 4697; b) Z. X. Wang, Y. C. Xu, Y. Y. Liu, L. Shao, J. Mater. Chem. A 2015, 3, 12171; c) B. Garcia, J. Saiz-Poseu, R. Gras-Charles, J. Hernando, R. Alibes, F. Novio, J. Sedo, F. Busque, D. Ruiz-Molina, ACS Appl. Mater. Interfaces 2014, 6, 17616.

[5] a) Q. M. Zhang, M. J. Serpe, ACS Appl. Mater. Interfaces 2015, 7, 27547; b) M. Krogsgaard, M. A. Behrens, J. S. Pedersen, H. Birkedal, Biomacromolecules 2013, 14, 297; c) N. Holten-Andersen, M. J. Harrington, H. Birkedal, B. P. Lee, P. B. Messersmith, K. Y. C. Lee, J. H. Waite, Proc. Natl. Acad. Sci. USA 2011, 108, 2651.

[6] H.-C. Yang, J. Luo, Y. Lv, P. Shen, Z.-K. Xu, J. Membr. Sci. 2015, 483, 42.

[7] a) E. Faure, C. Falentin-Daudre, C. Jerome, J. Lyskawa, D. Fournier, P. Woisel, C. Detrembleur, Prog. Polym. Sci. 2013, 38, 236; b) D. G. Barrett, T. S. Sileika, P. B. Messersmith, Chem. Commun. 2014, 50, 7265.

[8] Q. Wei, F. L. Zhang, J. Li, B. J. Li, C. S. Zhao, Polym. Chem. 2010, $1,1430$.

[9] X. Du, L. X. Li, J. S. Li, C. W. Yang, N. Frenkel, A. Welle, S. Heissler, A. Nefedov, M. Grunze, P. A. Levkin, Adv. Mater. 2014, 26, 8029.

[10] a) W.-Z. Qiu, Q.-Z. Zhong, Y. Du, Y. Lv, Z.-K. Xu, Green Chem. 2016, 18, 6205; b) J. R. Jeon, T. T. Le, Y. S. Chang, Microb. Biotechnol. 2016, 9, 305; c) C. Dhand, S. Harini, M. Venkatesh, N. Dwivedi, A. Ng, S. P. Liu, N. K. Verma, S. Ramakrishna, R. W. Beuerman, X. J. Loh, R. Lakshminarayanan, ACS Appl. Mater. Interfaces 2016, 8, 1220; d) J. R. Jeon, J. H. Kim, Y. S. Chang, J. Mater. Chem. B 2013, 1, 6501.

[11] a) S. Y. Huang, Y. Zhang, J. F. Shi, W. P. Huang, ACS Sustainable Chem. Eng. 2016, 4, 676; b) L. W. Yang, L. L. Han, J. Ren, H. L. Wei, L. Y. Jia, Colloids Surf., A 2015, 484, 197; c) C. Tang, D. Amin, P. B. Messersmith, J. E. Anthony, R. K. Prad'homme, Langmuir 2015, 31, 3612; d) M. A. Rahim, H. Ejima, K. L. Cho, K. Kempe, M. Mullner, J. P. Best, F. Caruso, Chem. Mater. 2014, 26, 1645; e) J. Guo, Y. Ping, H. Ejima, K. Alt, M. Meissner, J. J. Richardson, Y. Yan, K. Peter, D. von Elverfeldt, C. E. Hagemeyer, F. Caruso, Angew. Chem., Int. Ed. Engl. 2014, 53, 5546; f) H. Ejima, J. J. Richardson, K. Liang, J. P. Best, M. P. van Koeverden, G. K. Such, J. W. Cui, F. Caruso, Science 2013, 341, 154.

[12] a) S. H. Zhang, Z. Y. Jiang, X. L. Wang, C. Yang, J. F. Shi, ACS Appl. Mater. Interfaces 2015, 7, 19570; b) D. Pranantyo, L. Q. Xu, K. G. Neoh, E. T. Kang, Y. X. Ng, S. L. M. Teo, Biomacromolecules 2015, 16, 723; c) T. S. Sileika, D. G. Barrett, R. Zhang, K. H. A. Lau, P. B. Messersmith, Angew. Chem., Int. Ed. Engl. 2013, 52, 10766.

[13] Q. Wei, R. Haag, Mater. Horiz. 2015, 2, 567.

[14] J. Dai, R. J. Mumper, Molecules 2010, 15, 7313.

[15] K. B. Pandey, S. I. Rizvi, Oxid. Med. Cell. Longevity 2009, 2, 270.

[16] J.-R. Jeon, J.-H. Kim, Y.-S. Chang, J. Mater. Chem. B 2013, 1, 6501.

[17] S. Quideau, D. Deffieux, C. Douat-Casassus, L. Pouysegu, Angew. Chem., Int. Ed. Engl. 2011, 50, 586.

[18] M. M. Cowan, Clin. Microbiol. Rev. 1999, 12, 564.

[19] J. Genzer, R. R. Bhat, Langmuir 2008, 24, 2294.
[20] D. Mark, S. Haeberle, G. Roth, F. von Stetten, R. Zengerle, Chem. Soc. Rev. 2010, 39, 1153.

[21] a) C. Cruces-Blanco, L. Gamiz-Gracia, A. M. Garcia-Campana, TrAC, Trends Anal. Chem. 2007, 26, 215; b) K. Kawamura, T. Yasuda, T. Hatanaka, K. Hamahiga, N. Matsuda, M. Ueshima, K. Nakai, Chem. Eng. J. 2017, 307, 1066.

[22] a) M. Hitzbleck, L. Gervais, E. Delamarche, Lab Chip 2011, 11, 2680; b) P. C. Warnke, J. Timmer, C. B. Ostertag, K. Kopitzki, Ann. Neurol. 2005, 57, 136.

[23] a) F. R. de Souza, G. L. Alves, W. K. Coltro, Anal. Chem. 2012, 84, 9002; b) J. L. Krleza, A. Dorotic, A. Grzunov, M. Maradin, Biochem. Med. 2015, 25, 335.

[24] Z. Zhu, J. J. Lu, S. Liu, Anal. Chim. Acta 2012, 709, 21.

[25] X. Du, L. Li, F. Behboodi-Sadabad, A. Welle, J. Li, S. Heissler, H. Zhang, N. Plumeré, P. A. Levkin, Polym. Chem. 2017 DOI: 10.1039/C7PY00051K.

[26] N. Balasundram, K. Sundram, S. Samman, Food Chem. 2006, 99, 191.

[27] a) E. Haslam, Phytochemistry 2003, 64, 61; b) J. W. Drynan, M. N. Clifford, J. Obuchowicz, N. Kuhnert, Nat. Prod. Rep. 2010, 27, 417; c) S. Kobayashi, H. Higashimura, Prog. Polym. Sci. 2003, 28, 1015; d) S. Kobayashi, A. Makino, Chem. Rev. 2009, 109, 5288.

[28] a) A. Q. Hou, G. C. Feng, J. Y. Zhuo, G. Sun, ACS Appl. Mater. Interfaces 2015, 7, 27918; b) U. Wolfle, P. R. Esser, B. Simon-Haarhaus, S. F. Martin, J. Lademann, C. M. Schempp, Free Radical Biol. Med. 2011, 50, 1081; c) T. Herrling, K. Jung, J. Fuchs, Spectrochim. Acta, Part A 2006, 63, 840.

[29] a) S. Hong, J. Yeom, I. T. Song, S. M. Kang, H. Lee, H. Lee, Adv. Mater. Interfaces 2014, 1; b) J. S. Wright, E. R. Johnson, G. A. DiLabio, J. Am. Chem. Soc. 2001, 123, 1173.

[30] a) Z. H. Zhang, B. D. Goldstein, G. Witz, Biochem. Pharmacol. 1995, 50, 1607; b) L. G. Littlefield, E. E. Joiner, S. P. Colyer, A. M. Sayer, E. L. Frome, Int. J. Radiat Biol. 1988, 53, 875; C) M. Wasil, B. Halliwell, M. Grootveld, C. P. Moorhouse, D. C. S. Hutchison, H. Baum, Biochem. J. 1987, 243, 867.

[31] a) J. L. Yang, L. C. Wang, C. Y. Chang, T. Y. Liu, Environ. Mol. Mutagen. 1999, 33, 194; b) P. B. Merkel, D. R. Kearns, R. Nilsson, J. Am. Chem. Soc. 1972, 94, 1030; c) T. Kajiwara, D. R. Kearns, J. Am. Chem. Soc. 1973, 95, 5886; d) U. Takahama, Plant Cell Physiol. 1983, 24, 495.

[32] K. Halake, M. Birajdar, J. Lee, J. Ind. Eng. Chem. 2016, 35, 1.

[33] R. Abdel-Hamid, E. F. Newair, J. Electroanal. Chem. 2011, 657, 107.

[34] H. Hotta, S. Nagano, M. Ueda, Y. Tsujino, J. Koyama, T. Osakai, Biochim. Biophys. Acta, Gen. Subj. 2002, 1572, 123.

[35] a) R. Arakawa, M. Yamaguchi, H. Hotta, T. Osakai, T. Kimoto, J. Am. Soc. Mass Spectrom. 2004, 15, 1228; b) H. Fulcrand, A. Cheminat, R. Brouillard, V. Cheynier, Phytochemistry 1994, 35, 499.

[36] H. Hotta, H. Sakamoto, S. Nagano, T. Osakai, Y. Tsujino, Biochim. Biophys. Acta, Gen. Subj. 2001, 1526, 159.

[37] F. Parrino, A. Di Paola, V. Loddo, I. Pibiri, M. Bellardita, L. Palmisano, Appl. Catal., B 2016, 182, 347.

[38] a) K. Zheng, L. Zhang, Y. H. Gao, Y. F. Wu, W. S. Zhao, Y. C. Cui, J. Appl. Polym. Sci. 2015, 132, 9; b) M. Krogsgaard, A. Andersen, H. Birkedal, Chem. Commun. 2014, 50, 13278.

[39] J. R. Jeon, P. Baldrian, K. Murugesan, Y. S. Chang, Microb. Biotechnol. 2012, 5, 318.

[40] C. M. Preuss, M. M. Zieger, C. Rodriguez-Emmenegger, N. Zydziak, V. Trouillet, A. S. Goldmann, C. Barner-Kowollik, ACS Macro Lett. 2014, 3, 1169.

[41] L. X. Li, J. S. Li, X. Du, A. Welle, M. Grunze, O. Trapp, P. A. Levkin, Angew. Chem., Int. Ed. Engl. 2014, 53, 3835.

[42] C. Manach, A. Scalbert, C. Morand, C. Remesy, L. Jimenez, Am. J. Clin. Nutr. 2004, 79, 727. 
[43] a) M. Cazzola, I. Corazzari, E. Prenesti, E. Bertone, E. Verne, S. Ferraris, Appl. Surf. Sci. 2016, 367, 237; b) Z. M. Wang, C. L. Xu, X. Li, Z. H. Liu, Colloids Surf., A 2015, 485, 102; c) C. Das, B. Jain, K. Krishnamoorthy, Chem. Commun. 2015, 51, 11662; d) H. Wang, L. Chen, L. L. Weng, M. Y. Zhang, Q. Shen, J. Adhes. Sci. Technol. 2014, 28, 2416.
[44] F. L. Geyer, E. Ueda, U. Liebel, N. Grau, P. A. Levkin, Angew. Chem., Int. Ed. Engl. 2011, 50, 8424.

[45] K. L. Parry, A. G. Shard, R. D. Short, R. G. White, J. D. Whittle, A. Wright, Surf. Interface Anal. 2006, 38, 1497.

[46] J. H. Scofield, J. Electron Spectrosc. Relat. Phenom. 1976, 8, 129. 
Karlsruher Institut für Technologie

\section{Repository KITopen}

Dies ist ein Postprint/begutachtetes Manuskript.

Empfohlene Zitierung:

Behboodi-Sadabad, F.; Zhang, H.; Trouillet, V.; Welle, A.; Plumeré, N.; Levkin, P. A. UV-Triggered Polymerization, Deposition, and Patterning of Plant Phenolic Compounds. 2017. Advanced functional materials, 27. DOI:10.5445/IR/1000069397

Zitierung der Originalveröffentlichung:

Behboodi-Sadabad, F.; Zhang, H.; Trouillet, V.; Welle, A.; Plumeré, N.; Levkin, P. A. UV-Triggered Polymerization, Deposition, and Patterning of Plant Phenolic Compounds. 2017. Advanced functional materials, 27 (22), Art. Nr. 1700127.

DOI:10.1002/adfm.201700127 